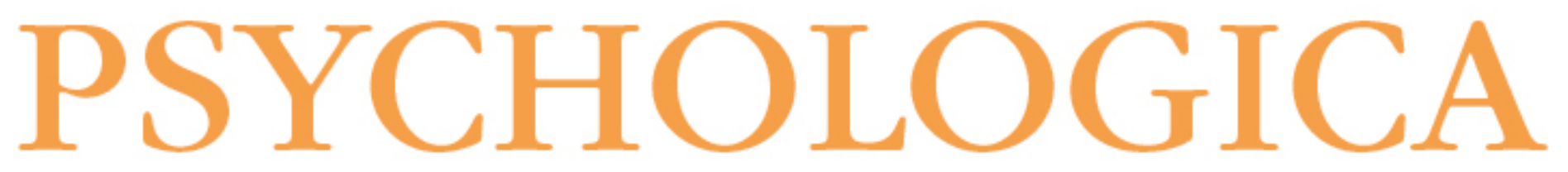

Era uma vez a Instituição onde eu vivi: narrativas de adultos sobre experiências de institucionalização

Autor(es): $\quad$ Quintãns, Cláudia; Alberto, Isabel; Machado, Carla

Publicado por: Imprensa da Universidade de Coimbra

URL

persistente: URI:http://hdl.handle.net/10316.2/5533

DOI: DOI:http://dx.doi.org/10.14195/1647-8606_53_16

Accessed : $\quad$ 26-Apr-2023 15:52:21

A navegação consulta e descarregamento dos títulos inseridos nas Bibliotecas Digitais UC Digitalis, UC Pombalina e UC Impactum, pressupõem a aceitação plena e sem reservas dos Termos e Condições de Uso destas Bibliotecas Digitais, disponíveis em https://digitalis.uc.pt/pt-pt/termos.

Conforme exposto nos referidos Termos e Condições de Uso, o descarregamento de títulos de acesso restrito requer uma licença válida de autorização devendo o utilizador aceder ao(s) documento(s) a partir de um endereço de IP da instituição detentora da supramencionada licença.

Ao utilizador é apenas permitido o descarregamento para uso pessoal, pelo que o emprego do(s) título(s) descarregado(s) para outro fim, designadamente comercial, carece de autorização do respetivo autor ou editor da obra.

Na medida em que todas as obras da UC Digitalis se encontram protegidas pelo Código do Direito de Autor e Direitos Conexos e demais legislação aplicável, toda a cópia, parcial ou total, deste documento, nos casos em que é legalmente admitida, deverá conter ou fazer-se acompanhar por este aviso. 
NÚMERO 53

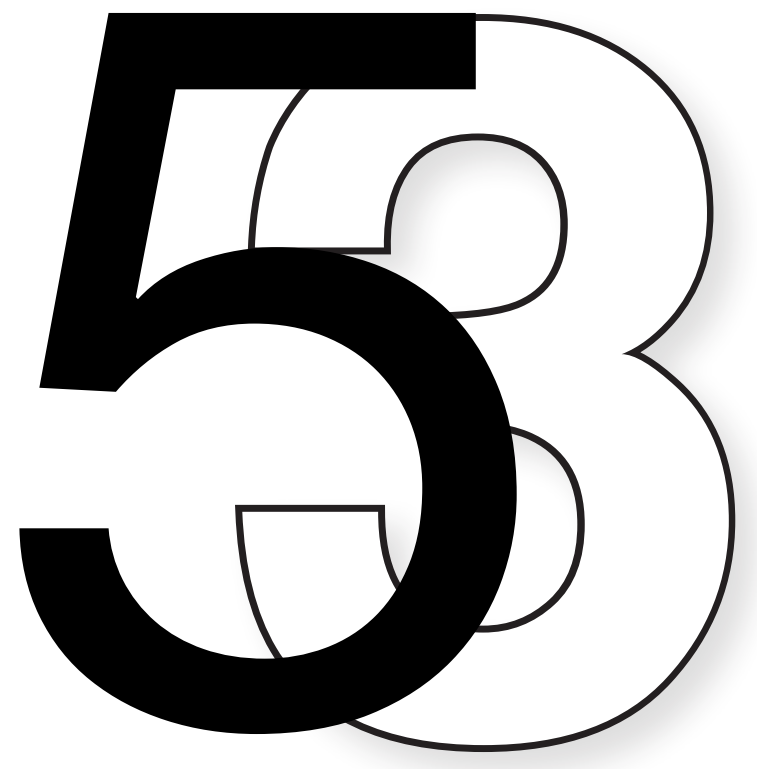

IMPRENSA DA UNIVERSIDADE DE COIMBRA

FACULDADE DE PSICOLOGIA E DE CIÊNCIAS DA EDUCAÇÃO DA UNIVERSIDADE DE COIMBRA 


\title{
Era uma vez a Instituição onde eu vivi: Narrativas de adultos sobre experiências de institucionalização
}

\author{
Cláudia Quintãns', Isabel Alberto² \& Carla Machado³
}

O estudo apresentado neste artigo teve como objectivo conhecer as narrativas de adultos que foram alvo de institucionalização na sua infância e/ou adolescência, em duas condições distintas: i) acolhimento prolongado em Lar de Infância e Juventude, após terem sido identificados como vítimas de maus-tratos e ii) colocação em Centro Educativo, após a sua identificação como autores de facto(s) qualificado(s) como crime pela Lei Penal Portuguesa. Foram recolhidas as narrativas de catorze participantes, salientando o que percepcionaram como aspectos positivos e como aspectos negativos da experiência de institucionalização, as suas vivências da mesma, bem como sugestões no sentido de melhorar a qualidade destes serviços.

Os resultados sugerem que a institucionalização comporta aspectos positivos e negativos, que foram claramente enunciados pelos participantes do nosso estudo.

PALAVRAS-CHAVE: institucionalização, percursos, percepções, narrativas.

As instituições para crianças e jovens, bem como as modalidades de apoio e assistência que as integram, reflectem em cada época a conjuntura política, as mutações sociais e as preocupações que a sociedade dedica a esta temática.

No Sistema Legal Português há duas grandes vertentes que definem a institucionalização de crianças e adolescentes: a) a promoção e protecção de crianças vítimas de abuso e/ou negligência, b) a institucionalização dos adolescentes que cometem actos tipificados como crime. Em Portugal existem cerca de 11.200 crianças acolhidas em instituição, sendo que destas, cerca de 9.000 se encontram em Lares de Infância e Juventude (CDSS, PII, 2006), o que traduz uma grande prevalência de crianças e jovens em acolhimento residencial, implicando a necessidade de se efectuarem estudos sobre esta medida. Em Centro educativo encontravam-se

\footnotetext{
1 Mestre pela Escola de Psicologia da Universidade do Minho

2 Faculdade de Psicologia e Ciências da Educação da Universidade de Coimbra - isamaria@fpce.uc.pt

3 Escola de Psicologia da Universidade do Minho
} 
267 jovens em regime de internamento em CE no ano de 2006 e 203 jovens em 2007 (Direcção Geral de Política de Justiça, MJ, 2007).

Portugal, juntamente com a Espanha e a Grécia, figura entre os países da União Europeia com maior percentagem de crianças e jovens sob cuidados residenciais evidenciando uma resposta lenta de busca de alternativas, comparativamente a outros países (Madge, 1994). Apesar do elevado número de crianças e jovens institucionalizados, é pouca a investigação relevante sobre o tema no nosso país (Martins, 2004) e mais raros ainda os estudos que incidem sobre a perspectiva e as narrativas das próprias crianças e jovens acolhidos.

Partindo da metáfora baseada na história de Hansel e Gretel (Martins, 2004), podemos dizer que o foco de interesse desta investigação é perceber como é viver na casinha de chocolate - a instituição -, conhecê-la melhor através das percepções de quem por lá passou. Os protagonistas desta investigação, são as próprias pessoas que viveram, no seu passado, numa casa de chocolate - Lar de acolhimento ou Centro Educativo - contando, na primeira pessoa, as suas vivências e experiências.

Fazendo eco das "vozes" destas pessoas, o presente estudo tem como objectivo compreender como é viver numa instituição, contribuindo para a promoção de novos olhares, e deste modo, de mudanças qualitativas nesta área, ainda tão pouco explorada no nosso país.

\section{As Instituições de acolhimento: breve caracterização}

Não se afigura fácil estabelecer uma definição operativa de instituição, tarefa que levanta algumas dificuldades (Mosteirin, 1999). Na área da Justiça, a mais famosa teorização sobre as instituições foi a produzida por Goffman (1974, cit. in Carvalho, 1999, p.31), no seu livro Asylums (1974), a propósito do conceito de instituição total, definida como:

\footnotetext{
"Um lugar de residência e de trabalho onde grande número de indivíduos, colocados na mesma situação, cortados do mundo exterior por um período relativamente longo, levam em conjunto uma vida fechada cujas modalidades são explícitas e minuciosamente reguladas".
}

Nesta concepção de instituição, Goffman sublinha o seu carácter fechado e a ruptura das pessoas que a integram, com a vida em sociedade. Sandomingo (1998) apresenta como especificidade das instituições destinadas ao acolhimento de crianças e jovens, o facto de serem "criadas pela iniciativa pública ou privada para facilitar uma atenção especializada àquelas crianças e jovens que, por cir- 
cunstâncias familiares distintas, necessitem de ser separados temporariamente do seu núcleo familiar, e para os quais o internamento é a opção preferencial face à impossibilidade de lhes oferecer outro tipo de recursos" (p. 71).

A definição dada por este autor parece-nos ser bastante adequada e abrangente, no sentido em que contempla diversas problemáticas (maus-tratos, delinquência, etc.), que radicam no núcleo familiar, como possíveis motivos de institucionalização e reconhece os possíveis estatutos de uma instituição (entidade pública ou privada). Todavia, não pressupõe o acolhimento prolongado característico dos Lares de Infância e Juventude em Portugal.

Sandomingo (1998) adianta uma classificação dos equipamentos institucionais em função da população atendida, tendo em conta dois grandes tipos:

a) Situação de desprotecção social: aqueles que devem garantir o desenvolvimento normal e harmonioso de cada menor quando este carece de uma família que o acolha ou quando esta não estabelece com aquele os vínculos parento-filiais adequados.

b) Situação de conflito social: aqueles que acolhem menores com medidas de internamento ditadas pelos Tribunais de Menores.

\section{Riscos e potencialidades das instituições}

\subsection{Riscos e fragilidades}

O processo de institucionalização de uma criança ou jovem pressupõe alguns riscos que, se não forem devidamente acautelados, poderão prejudicar o efeito pretendido pela institucionalização, ou seja, a "protecção" e/ou a sua "educação para o direito". Por vezes, "os sistemas desenhados para aliviar os problemas acabam por perpetuá-los e os serviços de ajuda podem, muitas vezes contribuir para os problemas que deveriam combater" (Sousa, 2005, p.50).

Justifica-se assim, uma reflexão sobre algumas dimensões intimamente ligadas ao processo de institucionalização que podem gerar problemas no funcionamento institucional, com consequências negativas para todos os intervenientes.

\subsubsection{Etiquetagem}

A criança ou jovem, a partir do momento em que é sinalizado e entra no sistema de protecção ou no sistema tutelar educativo, passa a ser identificado como "criança ou jovem em risco" ou como "jovem delinquente", o que, para além de 
poder ser vivido como uma forma de humilhação, faz com que estes sistemas coloquem em prática um processo complexo de etiquetagem, conferindo a estas crianças/jovens um estatuto social desvalorizado, transformando as pessoas em "clientes" e convertendo uma heterogeneidade de situações e vivências numa homogeneidade (Dias, 1998), o que tem como consequência a discriminação e a estigmatização de uma população já de si vulnerável (Taylor, 2004).

\subsubsection{Reprodução das desigualdades sociais}

O processo de institucionalização de crianças e jovens vítimas de violência ou autoras de crimes, parece ter subjacentes mecanismos de selecção mais associados "à sua família de origem numa esfera sócio-económica marcada pela precariedade de meios que caracterizam os seus modos de vida e os dos respectivos núcleos familiares" (Carvalho, 1999, p.38), do que propriamente à situação de maltrato ou crime. Efectivamente, "admite-se a existência de maltrato em todos as classes sociais, mas as populações institucionalizadas reflectem apenas os estratos socioeconómicos mais desfavorecidos (Alberto, 2008, p.213).

\subsubsection{Imagem depreciada das instituições para crianças e jovens}

Fernández del Valle (1992) alerta para o risco de, em face da crítica generalizada às respostas institucionais, estas tenderem a realizar a profecia originada pela ideia "não havia mais nada disponível»: preteridas como recurso em vias de extinção, sem investimento político, técnico ou financeiro, poderão vir a carecer de programas de intervenção que garantam respostas de qualidade, correspondendo assim ao papel que Ihes é atribuído. A desvalorização do seu estatuto tem tradução ao nível das equipas e dos profissionais que prestam serviços, ao nível da sua remuneração, formação e condições de trabalho e, por conseguinte, nas crianças e jovens que ganham consciência e vivenciam os estereótipos negativos através dos quais são percebidas.

\subsection{4. (Des)continuidade das relações afectivas}

As relações afectivas contínuas são as bases primárias mais importantes para o desenvolvimento das capacidades essenciais da criança, intelectuais, sociais e morais (Brazelton \& Greenspan, 2002). O que acontece frequentemente nos percursos de vida das crianças e adolescentes vítimas ou agressoras é a ausência ou a distorção destas relações que se esperavam organizadoras e o acolhimento institucional pode acrescer e multiplicar o carácter paradoxal das suas vivências (Martins, 2005). 
A partir do momento em que a criança/adolescente é separada do seu meio familiar e social e colocada numa instituição, dá-se uma ruptura com a rede de relações construídas até ao momento da institucionalização, o que possibilita uma vivência subjectiva de afastamento e abandono relativamente à família, com as atribuições depreciativas e de auto-desvalorização que tal separação pode motivar (Alberto, 2008). Simultaneamente, na instituição são assegurados um afecto e uma disponibilidade "em serviço", racionais e racionalizados, sem relações de pertença, em que os adultos se defendem do investimento afectivo da criança, tão necessário à sua sobrevivência psíquica e ao seu desenvolvimento. Assim, oferecem-se como modelos de referência assépticos, que se pretendem profissionalmente envolvidos e pessoalmente descomprometidos (Martins, 2001).

Um outro factor reforçador da descontinuidade dos laços afectivos é o facto de, nas instituições, se constatar muitas vezes a descontinuidade dos profissionais que lá trabalham (Taylor, 2004) originando nas crianças e jovens o sentimento de falta de apoio mantido e consistente, podendo isso " reforçar a ideia preexistente de que não há ninguém que realmente se interesse" (p.68) por eles.

\subsubsection{Distanciamento físico do meio de origem}

O acolhimento na instituição é frequentemente longe da zona de origem das crianças e jovens, dependendo mais das disponibilidades do momento do que das características da instituição e do indivíduo (Carvalho, 1999). Esta situação é altamente prejudicial, dificultando a manutenção e/ou promoção da relação com a família, e atendendo ao facto de que ele(a) regressará, mais tarde ou mais cedo, a esse mesmo meio (Cóias, 1995).

\subsubsection{Processos de "mortificação do eu" (Goffman, 1974)}

Goffman (1974) considera que, a partir do momento em que um indivíduo entra na instituição, inicia-se um processo de "rebaixamentos, degradações, humilhações e profanações do eu" (p.24). Vejamos de que modo a instituição pode, ainda que sem intencionalidade, provocar estes efeitos:

a) "Barreiras entre o internado e o mundo externo": na medida em que a instituição perturba os papéis que a pessoa desempenha na vida civil, tanto no ciclo vital como nas rotinas diárias do indivíduo.

b) "Processos de admissão ou "boas-vindas"': ocorrem quando a equipa dirigente ou os internos - ou os dois grupos - procuram dar à pessoa recém-chegada uma noção clara da sua situação de subordinação. 
c) "Regulamentação de espaços e de tempos": a regulamentação espacial e temporal que constitui a rotina da instituição, se por um lado tem uma dimensão positiva - securizante e organizadora - para as crianças e jovens, por outro, pode tornar-se invasora da definição do espaço próprio (Alberto, 2008) e corre-se o risco de os despojar da sua própria individualidade (Carvalho, 1999).

d) "Deferência obrigatória": ocorre quando as pessoas que estão institucionalizadas são obrigadas, na sua interacção social com a equipa directiva (ou técnica), a apresentar actos verbais de deferência (por exemplo, dizendo "senhor" ou "doutor" a todo o momento). Também surge quando se é obrigado a participar em rotinas diárias com as quais a criança não está familiarizada e com as quais não se identifica.

e) "Ataque ao status do internado como actor social": numa instituição total os mínimos segmentos da actividade podem estar sujeitos a regulamentos e julgamentos e a vida do indivíduo é constantemente avassalada pela hipótese de uma sanção vinda de cima, invadindo-se a autonomia das acções.

\subsubsection{Problemas de funcionamento da equipa de funcionários ou monitores}

Os profissionais são um recurso que a instituição incorpora para alcançar os seus objectivos e, portanto, devem satisfazer as condições de formação, prática e idoneidade física e psíquica. No entanto, é muito frequente haver a contratação de pessoal para contactar directamente com as crianças/adolescentes que foi dispensado de uma outra área ou carece da formação necessária e, algumas vezes até com diagnóstico médico ou psicológico limitativo para esse trabalho (Souza, 1987, cit. por Teixeira, 1993). Esta situação é agravada pela inexistência de investigações fiáveis que permitam afirmar quais são os recursos mínimos para a realização de uma tarefa de cuidado institucional, no diz respeito tanto a instalações como a serviços e recursos humanos (Mosteirin, 2000).

\subsubsection{Ausência de uma intervenção terapêutica}

Estudos efectuados no Reino Unido verificaram uma escassez de serviços terapêuticos oferecidos às crianças e jovens nos serviços residenciais (Berridge \& Brodie, 1998).

Berger (1998) considera que se verifica uma focalização na resolução social dos casos de protecção, em detrimento da acção psicoterapêutica e psicoeducativa, alertando para o efeito protector/reabilitador da separação da criança/adolescente, 
porém ineficaz na reparação das perturbações e na resolução dos problemas psicológicos destas crianças.

\subsubsection{Abusos físicos, emocionais e sexuais}

A pouca pesquisa disponível sobre este tema é coerente na constatação de dois

\subsubsection{Fraco apoio na saída e pós-colocação}

A investigação realizada neste domínio realça a vulnerabilidade dos jovens que saem do sistema residencial relativamente a situações futuras de exclusão social, absentismo escolar e sem-abrigo (Unidade de Exclusão Social, cit. Taylor, 2004). Verifica-se também uma associação entre a desinstitucionalização e o maior envolvimento em actividades criminais, risco acrescido de dependência da segurança social (McDonald et al., 1996), mudanças de residência mais frequentes, condições de habitabilidade mais fracas, sobre-representação entre os sem-abrigo e número elevado de gravidezes precoces (idem, 1996).

\subsection{Potencialidades e oportunidades}

A institucionalização tem também um conjunto de potencialidades que um olhar positivo e construtivo deve atender, enquanto oportunidade de ganhos efectivos para a criança e para a sua família. Para que uma instituição proporcione condições de desenvolvimento e realização pessoal, Raymond (1996) defende que: "só o poderá fazer se estiver consciente de si mesma, dos seus objectivos, dos métodos de tratamento e da coerência interna da sua equipa" (p.26).

Partindo dos trabalhos de Raymond (1996ab, 1998, 1999), considera-se que uma instituição constitui um "invólucro" que permite o acompanhamento a diversos níveis, interdependentes entre si, realizando um conjunto de funções:

a) "Moderação": a instituição assume uma função do tipo "pára-choques", sustendo, protegendo, envolvendo. Esta função é concretizada através do enquadramento (local e espaço físico, ritmo de vida individual e do grupo e regras) e do meio humano envolvente (crianças e jovens e os adultos que a compõem); 
b) "Contenção": quando a instituição recebe e transforma as experiências das crianças e jovens em representações e em pensamentos aceitáveis, através dos adultos que nela trabalham. Os adultos preenchem esta função contentora não reagindo como os jovens, não respondendo a um insulto com outro insulto, e não utilizando a violência perante a cólera, não respondendo por actos face ao agir dos menores.

Além disso, uma instituição que acolhe crianças e jovens pode (e deve) ser

a) "Securizante", na medida em que compensa a desorganização, instabilidade e imprevisibilidade que normalmente caracterizam os contextos familiares destas crianças, regendo-se, por exemplo, pelo estabelecimento de regras e rotinas diárias conhecidas e horários estáveis e limites claramente definidos, reduzindo a imprevisibilidade, geradora de ansiedade (Medeiros \& Coelho, 1991). Para lá das regras e das rotinas, a instituição tem limites naturais no espaço físico que funcionam como protecção do exterior e, internamente ajudam a diferenciar os espaços e objectos pessoais, devendo ser, de forma concomitante, dinamizados por uma interacção afectuosa e acolhedora (Raymond, 1996);

b) “Contentora das angústias", através da atitude benevolente dos adultos, por atitudes de compreensão, empatia e tolerância, promovendo a expressão adequada de sentimentos e opiniões, facilitando a comunicação na diversidade das suas formas e o estabelecimento de relações (Raymond, 1998). Ainda no sentido de superar a angústia vivida pelas crianças e adolescentes, os adultos devem privilegiar o papel fundamental da informação, explicando os porquês, as razões de ser das regras, das situações, das relações, reduzindo assim a imprevisibilidade e a instabilidade, ajudando a criança/ jovem a construir uma imagem mais organizada, estável e controlável da realidade;

c) "Promotora do desenvolvimento pessoal e da construção da identidade", oferecendo a possibilidade de acompanhamento e tratamento, ao promover condições que possibilitem a (re)construção do eu, quer pela (re)formulação do passado, quer pela construção de projectos de futuro, acompanhada de uma reestruturação do auto-conceito. Este acompanhamento pode ser efectuado através de duas realidades: interna - no trabalho da realidade psíquica - e externa - pela interacção constante entre a criança/jovem e o ambiente que a rodeia (Raymond, 1998);

d) "Promotora de relacionamentos positivos", em que os esquemas de transformação estão em relação directa com a criação de vínculos e o trabalho institucional faz-se, essencialmente, graças aos laços que os adultos 
estabelecem com os jovens (Raymond, 1999) e dos laços entre os pares (Edmond, 2002).

Nesta óptica, o contributo que os cuidados residenciais podem oferecer pode não ser inferior aos das opções em alternativa, devendo, por isso, na opinião de Sinclair e Gibbs (1996), inverter-se a evolução actual de que estão a ser objecto, cuja lógica é questionável, nomeadamente constituírem uma opção de último recurso. Zurita e Fernández del Valle (1996) enumeram mesmo um conjunto de vantagens dos cuidados residenciais frente a outros tipos de medidas:

a) Ser sujeito a menos rupturas e adaptações mal sucedidas do que outros tipos de colocação;

b) Não solicitar, do mesmo modo que o acolhimento familiar, o estabelecimento de vínculos afectivos próximos com adultos, eventualmente sentidos pelas crianças e jovens como comprometedores da sua fidelidade às famílias de origem;

c) Poder facilitar o contacto pais-filhos e promover o envolvimento da família biológica, na medida em que o tipo de relações instituídas no acolhimento institucional são mais profissionais, contrastando com as dificuldades de relação frequentes entre, por exemplo, a família de acolhimento e a família biológica;

d) Constituírem contextos mais estruturados e organizados, com limites definidos para os comportamentos;

e) Possuírem uma capacidade de oferta de serviços especializados para o tratamento de problemáticas específicas, constituindo um contexto privilegiado para a realização de determinadas intervenções terapêuticas;

f) Através das experiências propiciadas pela vida em grupo, facilitam o estabelecimento de laços com pares e adultos, favorecem o desenvolvimento de sentimentos de pertença e de cooperação; promovem a interiorização de valores e padrões de condutas grupais e fomentam tarefas de socialização e de responsabilização (Vilaverde, 2000).

Em suma, a censura dos serviços residenciais não pode ser feita em termos absolutos e universais. Se, para a maioria das crianças, o internamento não constitui uma medida apropriada, para outras pode ser uma componente essencial da solução dos seus problemas e necessidades (Department of Health, 1998), desde que asseguradas as condições básicas que visam o seu bem-estar e a qualidade de vida, o que implica uma avaliação criteriosa das suas necessidades e uma monitorização cuidadosa da sua evolução. 


\section{Metodologia}

Neste estudo empírico analisámos as narrativas de adultos sobre experiências de institucionalização na sua infância e/ou adolescência. Como objectivos específicos, pretendíamos:

i) conhecer os processos representacionais dos sujeitos no que respeita a algumas dimensões do acolhimento institucional, bem como quanto ao momento de saída e ao período pós-colocação;

ii) identificar parâmetros de funcionamento institucional que forneçam pistas para a avaliação da qualidade destes serviços, através do que os sujeitos percepcionam como aspectos positivos e negativos desta experiência.

\subsection{Amostra}

A nossa amostra era constituída por indivíduos que foram alvo de institucionalização em duas condições distintas: i) acolhimento prolongado em Lar de Infância e Juventude, após terem sido identificados como vítimas de mau(s) trato(s) e ii) sujeitos que foram colocados em Centro Educativo, a pós a sua identificação como autores de facto(s) qualificado(s) como crime pela Lei Penal Portuguesa. Dada a dificuldade de acesso a esta população, numa primeira fase foram efectuados contactos com técnicos de instituições da região Centro, nomeadamente, Lares e Centros Educativos, bem como C.P.C.J.. A cada um dos técnicos foi pedido que nos facilitasse o contacto com um possível participante, que obedecesse aos seguintes critérios: 1) ter sido alvo de institucionalização no seu passado em Lar e/ou Centro Educativo e 2) o período de institucionalização ter sido superior a 6 meses. A selecção dos sujeitos atendeu ao preenchimento destes critérios bem como à sua disponibilidade para participar.

Numa segunda fase usámos a técnica de amostragem em bola de neve, com cada sujeito entrevistado identificando outro(s) jovens/adultos que tivessem vivido numa instituição do mesmo tipo (Lar/Centro Educativo) e assim sucessivamente. Assim, foram sendo construídas cadeias que se prolongaram (ou não) de acordo com a (in)disponibilidade dos sujeitos para participar no estudo. Foram constituidas 4 cadeias com participantes que foram alvo de institucionalização em Lares, perfazendo um total de 10 elementos e 4 participantes que foram institucionalizados em Centros Educativos. Nesta última sub-amostra as cadeias não tiveram continuidade devido, por um lado, à indisponibilidade das pessoas contactadas em participar na investigação, e por outro, à falta de contactos que deveriam ser obtidos através dos participantes. 


\subsection{Instrumentos}

Para recolha de informação, elaborámos um guião de entrevista semi-estruturado, em torno das questões centrais do nosso estudo. Para a construção do respectivo guião utilizámos as seguintes fontes:

a) a literatura disponivel sobre as características desta população e sobre as especificidades destas formas de acolhimento e

b) a experiência obtida no decurso do nosso percurso profissional neste tipo de instituições.

Este guião de entrevista pretendia aceder a três componentes da vivência da institucionalização:

1. as circunstâncias presentes na colocação institucional (motivo e o processo de entrada na instituição);

2. o percurso dentro da instituição (momento de chegada, rotinas, aspectos vividos como negativos e positivos, qualidade das interacções, etc.); e

3. as condições de saída da instituição e o percurso pós-institucionalização.

\subsection{Procedimentos}

A maior parte das entrevistas foram efectuadas num gabinete de apoio psicológico na região Centro e, quando tal não foi exequível, o investigador deslocou-se ao meio de origem dos sujeitos.

As entrevistas foram gravadas em áudio e duraram em média 90 minutos. Posteriormente, procedeu-se à sua transcrição integral.

\subsection{Análise dos dados}

A técnica de tratamento de dados utilizada foi a análise de conteúdo. O processo de codificação decorreu em duas fases distintas: a definição de categorias, criadas indutivamente a partir da codificação dos dados das entrevistas e, posteriormente, o teste de validade interna sobre a exclusividade e exaustividade das categorias encontradas.

Neste processo, adoptámos um critério semântico para a identificação das unidades de registo, tomando como unidade de contexto a entrevista individual de cada sujeito da amostra. A unidade de enumeração foi a contagem de ocorrências, isto é, a contagem do número de unidades de registo indexadas a cada categoria. $\mathrm{O}$ processamento da informação foi feito sem recurso a programas informáticos de tratamento ou categorização da informação. 


\section{Apresentação e discussão dos Resultados}

\subsection{Dimensões positivas identificadas}

Os participantes identificaram de forma clara e espontânea aspectos positivos no seu percurso institucional. Alguns manifestaram mesmo agrado em falar acerca deste tema, quer por "falar de um assunto que estava há muito fechado no armário", quer pela esperança de "poder ajudar outras pessoas que estão na mesma situação em que eu estive". Porém, um participante da amostra dos Lares de Infância e Juventude e outro da amostra dos Centros Educativos referiram não encontrar nenhum aspecto positivo na instituição onde estiveram (quadro 1). Os aspectos positivos mais enumerados por ambas as sub-amostras (quadro 1.) dizem respeito:

- Convivência e relacionamentos

"havia paz, havia companheirismo, havia amor, entre aspas, entre o pessoal (...) Eram amigos, tinham diálogo, tentavam ajudar (...) no X aprendi uma coisa:(...) Vale a pena um gajo ser amigo das pessoas."

A instituição surge, aqui, como promotora de relacionamentos positivos (Raymond, 1996) através das relações com os pares e os profissionais, constituindo o aspecto mais enumerado em ambas as sub-amostras e bastante valorizado pelos participantes.

- Percurso académico e profissional

"No Colégio, aprendi bastante - aprendi mais desde que acabei o curso - comecei a perceber as coisas de maneira diferente, tornei-me mais adulto, mudou completamente a minha vida"

Foi realçado pelos sujeitos da amostra que a instituição permitiu um percurso académico e profissional, que constituiu uma mais-valia primordial para as crianças e jovens institucionalizados, no sentido em que é condição para a sua integração socioprofissional presente e futura. Esta vantagem pode fazer a diferença no percurso de vida destes indivíduos uma vez que, frequentemente, não está acessível nos seus meios de origem. Este aspecto foi também dos mais relatados pelos participantes.

- Apoio na construção duma identidade pessoal

\footnotetext{
"o que sou, devo-o, ao meu esforço também claro mas, sobretudo, à Casa X. Não tive familia que tivesse possibilidade de me dar o que eu sou. (...) o essencial, a maneira de estar e encarar a vida foi cá que aprendi".
} 
Outra das potencialidades da institucionalização identificada nesta amostra, é o ser promotora do desenvolvimento pessoal e da formação da identidade (Raymond, 1996), sendo este aspecto reconhecido por grande parte dos participantes (quadro 1).

- Satisfação das necessidades básicas

"pelo menos aquelas crianças têm cama, roupa lavada e comida na mesa, já é muito bom. Nem todos o têm.".

Esta função foi a mais enumerada pela sub-amostra Lares, não tendo emergido na outra sub-amostra, o que se pode dever à não satisfação destas necessidades no contexto familiar, originando que os participantes valorizem bastante este aspecto. Assim, a instituição pode ser sentida como calorosa e securizante (Raymond, 1998), através da satisfação das necessidades básicas de alimentação, de acolhimento e de protecção e de afecto.

Quadro 1. Aspectos positivos referidos pelos sujeitos das duas sub-amostras - Lares de Infância e Juventude (L.I.J.) e Centros Educativos (C.E.)

\begin{tabular}{|c|c|c|c|}
\hline & (Sub)Categorias & L.I.J. & C.E. \\
\hline \multirow{10}{*}{ 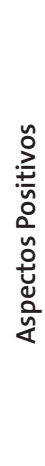 } & 1. Satisfação das necessidades básicas & & \\
\hline & Alimentação & 4 & \\
\hline & Acolhimento e protecção & 2 & \\
\hline & Afecto & 2 & \\
\hline & (Sub)total & (8) & \\
\hline & 2. Convivência e Relacionamentos & 7 & $5^{*}$ \\
\hline & 3. Percurso académico e profissional & 6 & 3 \\
\hline & 4. Apoio indispensável na formação da identidade & 6 & 2 \\
\hline & 5. Actividades lúdicas e desportivas & 2 & 2 \\
\hline & Total: & 29 & 12 \\
\hline
\end{tabular}

* Este número é superior ao número total de sujeitos porque um sujeito esteve em 3 instituições.

A instituição, tal como referimos, pode ter inúmeras potencialidades, que são percebidas e valorizadas pelos participantes como factores que promoveram mudanças qualitativamente positivas nos seus percursos de vida.

\subsection{Dimensões negativas identificadas}

Os participantes apontaram aspectos negativos da instituição, destacando-se nas suas narrativas uma forte activação emocional ao abordarem estes assuntos. 


\section{- Deferência obrigatória}

Foi o aspecto negativo mais referido por ambas as sub-amostras (cf quadro 2), reportando-se na sub-amostra L.I.J., especificamente à obrigatoriedade da participação em determinadas actividades, nomeadamente, actividades ligadas à igreja católica (e.g., ir à missa, à catequese, rezar, etc.) e em actividades e tarefas institucionais (e.g., oficinas e tarefas de limpeza).

"era obrigatório ir à missa ao domingo, mesmo para quem não queria, acho que está mal (...) eu posso não ser católico, ou acreditar em Deus mas não querer ir á missa dada pelo Sr. Padre"

Na sub-amostra C.E., a deferência obrigatória relaciona-se com a obrigatoriedade em apresentar actos verbais de deferência na interacção com a equipa directiva e/ou técnica.

"nós vivemos livremente na nossa casa, vamos a qualquer sitio não é? E agora vamos para um sitio onde temos de pedir para ir da sala para o quarto "Ó senhor, posso sair?", "Podes" (...) "Não, fica onde estás". É complicado"

Podemos assim constatar que um aspecto específico do acolhimento institucional, quer em Lar, quer em Centro Educativo, é o fenómeno de deferência obrigatória (Goffman, 1974), que no primeiro tipo de instituição se manifesta na obrigatoriedade de determinadas rotinas, consideradas pelos sujeitos como invasoras do espaço próprio (Alberto, 2008) e, no segundo tipo de instituição, pela obrigatoriedade em apresentar, diariamente, actos verbais de deferência, consideradas pelos sujeitos como algo difícil de concretizar e estranho à própria pessoa (Goffman, 1974).

- Os recursos humanos (nomeadamente, a ausência de afecto, a ausência de características adequadas à função desempenhada e a constante rotatividade)

“não me lembro de ter carinho (...) por isso é que muitas crianças fogem ou quando saem tornam-se pessoas esquisitas (...) quando precisava de uma festa ou de um carinho...não tinha"

Na sub-amostra dos Lares, alguns tópicos negativos salientados dizem respeito à ausência de afecto, que os participantes consideram não ter sido uma necessidade satisfeita por parte da instituição. Esta é uma função básica dos Lares de Infância e Juventude, ressalvada a nível legal, no art. $5^{\circ}$, no ponto 1 do Decreto-Lei n. ${ }^{\circ}$ 2/864: "O acolhimento dos lares deve obedecer a rigorosos critérios de admissão e salvaguardar sempre a individualidade das crianças e jovens, proporcionando-lhes

4 Publicado no D.R. n. ${ }^{\circ}$ 1/86, Série I, de 2 de Janeiro de 1986. 
as condições de afectividade, saúde, equilibrio emocional e educação que permitam o seu adequado desenvolvimento."

Os dados obtidos poderão ser explicados por vários factores: a) constituir um processo de defesa dos profissionais, que provavelmente pretendem manter uma relação distante e longínqua, sendo apenas “técnicos”, pelo que a criança/jovem não é investida (Martins, 2001; Raymond, 1998); b) falta de formação dos profissionais (Linares, 2002); c) características pessoais que não permitem defrontar as exigências do trabalho; d) condições laborais específicas, tais como, as circunstâncias de trabalho insatisfatórias, e/ou as remunerações baixas (Madge, 1994); e) falta de supervisão e f) procedimentos de recrutamento e selecção dos recursos humanos questionáveis, nomeadamente no que diz respeito à qualificação e às qualidades pessoais dos recursos humanos que se contratam para estas instituições (Ministério do Trabalho e da Solidariedade, 2000). A falta de qualificação e de formação da maior parte do pessoal que assegura o funcionamento nestes serviços, bem como a sua constante rotatividade, têm consequências inevitáveis ao nível da qualidade dos serviços prestados, bem como da estabilidade das próprias crianças (Madge, 1994).

\section{- Ser fechada ao exterior}

"não ter acesso ao mundo cá fora (...) porque eles, ao prenderem as pessoas, quando vêm cá para fora, a vida torna-se estranha para elas e muitas delas acabam por fazer coisas más"

Outro aspecto verbalizado especificamente na amostra dos Lares é o facto de ser fechada ao exterior, o que também contraria o estipulado no art. $6^{\circ}$ do DecretoLei n. ${ }^{\circ}$ 2/86, que refere que estas instituições “devem ser abertas à comunidade".

- Processo de saída (a obrigatoriedade da saída imediata, sem as condições básicas necessárias para tal e ausência de uma preparação adequada para a autonomia de vida)

- "mandarem assim uma pessoa embora, sem emprego e sem nada?!"

- "acho que deviam preparar em condições, porque uma rapariga quando sai de uma instituição tem de saber fazer o comer"

A referência à obrigatoriedade de saída imediata da instituição e a pouca preparação para a autonomia de vida e a ausência de apoio pós-colocação, teve da parte dos sujeitos da sub-amostra dos Lares uma especial atenção, reforçando a constatação de que, muitas vezes, estes jovens são forçados à independência (Broad, 1998, cit. por Taylor, 2004), mesmo que ainda não possuam as condições para tal. 


\section{- Ausência de apoio pós-saída}

"Eu ia almoçar (...) o Dr. nem me perguntava se eu estou bem (...) não consigo ir lá (...) não tenho apoio"

A finalidade do sistema de protecção é "propiciar condições para uma correcta inserção das crianças e jovens na comunidade através da sua integração nas estruturas locais, nomeadamente no que se refere a educação, formação profissional, desporto e tempos livres"(art. $6^{\circ}$, ponto 2 do Decreto-Lei n. $\left.{ }^{\circ} 2 / 86\right)$. Contudo, pelas narrativas dos sujeitos da sub-amostra dos Lares, este objectivo parece não ter sido cumprido.

Houve igualmente aspectos negativos especificamente referidos pelos sujeitos da sub-amostra C.E., tais como :

\section{- Pouca vigilância}

"Se houvesse mais vigilância, muitos dos problemas que houve naquele colégio não se tinham passado"

É surpreendente a percepção da pouca vigilância por parte dos participantes internados em CE. Enquadramos este dado no facto de alguns participantes terem estado institucionalizados antes da vigência da nova Lei Tutelar Educativa, num regime porventura menos atento às questões de segurança do que o actual.

\section{- Permanecer numa divisão fechada, sem contacto com pessoas}

“chorei muito (...) 3 dias e 3 noites (...) depois apagavam a luz e ficávamos na escuridão (...) muito mau...foi uma solidão...isso não provoca nada de bom, nem a mim nem a toda a gente que entra lá"

Sendo certo que o período de permanência em CE constitui uma ruptura com determinados padrões até então existentes - exigindo alguma reflexão por parte do jovem - a verificar-se este procedimento, urge questionar a sua função e efeitos. Segundo Goffman (1974), este pode ser um processo de boas-vindas e traduz a crença de que, se o internado for obrigado a mostrar uma extrema deferência no momento da admissão, será depois controlável, pois, ao submeter-se a essas exigências iniciais, a sua resistência é, de alguma forma, quebrada. Esta crença de senso comum não encontra, porém, sustentação na literatura da especialidade, a qual considera que apresentar a entrada na instituição como uma punição, conduz a uma recusa e oposição por parte do jovem. Parece ser preferível transmitir uma mensagem de esperança (I.P., CID, 2006), fazer ressaltar os aspectos positivos da vida num Lar/Centro Educativo (Raymond, 1998). 


\section{- Abusos (físicos, emocionais, sexuais, negligência)}

"foi um monitor, mas já passou... bateu-me muito com pontapés...isso foi o mais grave e fiquei a deitar sangue e tive que ir à enfermaria(...) Ele bateu-me porque eu não queria ir para a biblioteca."

Na sub-amostra CE, podemos verificar que 2 sujeitos referem terem vivido vários tipos de maus-tratos.

Considerando que crianças e adolescentes sob cuidados residenciais experienciaram frequentemente abusos e/ou negligência nas suas próprias casas, o mínimo que podem esperar é segurança face aos abusos quando estão sob os cuidados de uma instituição (Kendrick, 1998). Todavia, estas narrativas mostram que nem sempre essa segurança é estabelecida.

Quadro 2. Aspectos negativos percepcionados pelos sujeitos das duas sub-amostras - Lares de Infância e Juventude (L.I.J.) e Centros Educativos (C.E.)

\begin{tabular}{|c|c|c|c|}
\hline & (Sub)Categorias & $\begin{array}{l}\text { L.I.J. } \\
(\mathrm{N}=10)\end{array}$ & $\begin{array}{l}\text { C.E. } \\
(\mathrm{N}=4)\end{array}$ \\
\hline \multirow{18}{*}{ 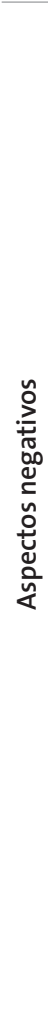 } & 1. Recursos humanos: & & \\
\hline & Ausência de afecto & 5 & \\
\hline & $\begin{array}{l}\text { Ausência das características da personalidade necessárias à } \\
\text { função desempenhada }\end{array}$ & 3 & \\
\hline & Rotatividade & 1 & \\
\hline & (Sub)total: & (9) & \\
\hline & 2. Pouca vigilância & & 3 \\
\hline & 3. Deferência obrigatória: & & \\
\hline & 3.1. Actividades obrigatórias & 5 & \\
\hline & 3.2. Actos verbais de deferência & & 2 \\
\hline & 4. Ser fechada ao exterior & 4 & \\
\hline & $\begin{array}{l}\text { 4.1. Permanecer numa divisão fechada, sem contacto com } \\
\text { os outros }\end{array}$ & & 3 \\
\hline & 5. Processo de saída: & & \\
\hline & 5.1. Obrigatoriedade da saída imediata & 4 & \\
\hline & $\begin{array}{l}\text { 5.2. Ausência de uma preparação adequada para a autono- } \\
\text { mia de vida }\end{array}$ & 4 & \\
\hline & (Sub)total: & (8) & \\
\hline & 6. Ausência de apoio pós-colocação & 4 & \\
\hline & 7. Abusos (físicos, emocionais, sexuais, negligência) & & 2 \\
\hline & Total: & 30 & 10 \\
\hline
\end{tabular}


Verifica-se (cf quadro 1 e 2) que os participantes da sub-amostra L.I.J. referem mais aspectos negativos e os participantes da sub-amostra C.E. referem mais aspectos positivos.

\subsection{Sugestões para melhorar o acolhimento institucional}

Finalmente, solicitámos aos entrevistados que sugerissem mudança(s) em relação ao internamento, questionando-os sobre o que fariam no caso de serem directores da instituição onde tinham sido acolhidos. Todos os participantes das duas sub-amostras enumeraram vários desejos de mudança no acolhimento institucional, apresentando sugestões claras e objectivas.

As sugestões de mudança mais frequentemente mencionados dizem respeito aos recursos humanos (LIJ, $n=11 ; C E, n=4$ ), nomeadamente: a) explicar e reflectir com a criança/jovem acerca das regras e outros assuntos ( $L I J=2 ; C E=1)$; $b$ ) haver mais psicólogos, proporcionar apoio psicológico e/ou psiquiátrico até ao momento de saída ( $L I J=2 ;(E=2) ; c)$ existir uma atenção mais individualizada para cada criança e uma maior compreensão, colocando mais adultos por cada grupo de crianças (LIJ,=4); d) uma educação mais actual (LIJ=2), e) formação e qualificação dos funcionários $(L I J=1)$ e f) proporcionar e execução de tarefas que sejam úteis aos jovens $(C E=1)$.

A oferta de melhor formação e qualificação profissional, bem como a inserção no mercado de trabalho foi mencionada por 7 sujeitos $(L I J=4 ; C E=3)$.

Na sub-amostra LIJ, 6 participantes indicam que determinadas rotinas não deveriam ser obrigatórias, designadamente, as de tipo religioso e as tarefas institucionais.

No que concerne ao espaço físico, 5 participantes ( $L I J=3 ; C E=2)$ aconselham a construção de casas familiares (em detrimento de construções de grandes dimensões): "Deveria fazer um espaço mais pequenino e ter uma figura de mãe e pai". Enquanto os sujeitos dos LIJ sugerem a criação de estruturas físicas diferenciadas consoante as idades das crianças/jovens, os dos CE indicam a existência de menos luxo nas instalações.

Por último, sobressai a necessidade de uma maior abertura e flexibilidade das regras (LIJ=4), por exemplo, "em vez de não se poder ter namorado (e esconder), ter a informação necessária e tomar precauções, em vez de não se poder sair, poder sair de vez em quando", em vez de ser proibido ver filmes considerados tabu (e determinadas cenas dos filmes serem cortadas), vê-los em conjunto e falar-se sobre isso".

Na sub-amostra CE surge ainda a importância de terminar com o procedimento, no momento da chegada, de manterem os jovens isolados no quarto fechado $(n=2)$ : "no inicio, quando a pessoa lá entra, acha que temos mesmo de nos meter 3 
dias num quarto? Porquê?" e o promover o relacionamento com a família biológica $(n=2)$ : "em vez de estar no ano inteiro e só ir lá nas férias do Verão, ir passar os fins-de-semana a casa, ir passar umas semanas...estar institucionalizado mas sem nunca perder os laços familiares".

\section{Sintese}

A institucionalização de crianças e adolescentes vítimas de maltrato e autoras de factos qualificados como crime tem sido um tema "esquecido" no domínio científico até há bem pouco tempo, sendo raras as referências teóricas a este tema. Esta temática tem sido alvo de algumas investigações nos últimos anos, todavia, há ainda um longo caminho a percorrer, quer no que respeita ao domínio científico, quer no que concerne às questões sociais, políticas e ideológicas que o enquadram e influenciam.

É interessante notar que todos os participantes do estudo percepcionaram aspectos positivos e negativos do acolhimento institucional, muitos dos quais correspondem a factores referenciados pela investigação teórica. Apresentaram ainda sugestões concretas e pertinentes que, na sua opinião, e também na nossa, contribuirão para melhorar o sistema de acolhimento institucional no nosso país.

Da análise e discussão das informações recolhidas das narrativas destes adultos que tiveram percursos de institucionalização na sua infância e/ou adolescência há vários tópicos a destacar, nomeadamente:

Como aspectos positivos (que urge valorizar) surgiram: a) o papel fundamental das relações proporcionadas pelo acolhimento institucional, quer seja com os pares, funcionários ou equipa técnica e/ou directiva; b) o percurso académico e profissional, a que provavelmente não teriam acesso no contexto familiar e c) o papel da instituição na formação da identidade destas crianças e jovens.

Como aspectos negativos (que urge alterar) emanaram: a) ao nível dos recursos humanos, quando se verifica uma falta de investimento e as instituições não oferecem alternativas relacionais estruturantes e securizantes; b) a função de controlo privilegiada nalgumas instituições - tal como com o fenómeno de deferência obrigatória e/ou quando a sua estrutura e normas de funcionamento são sentidas como demasiado "rígidas", por vezes até invasores do espaço próprio; c) a ocorrência de maus-tratos, permitindo uma (re)vitimização das crianças, já por si bastante vulneráveis e d) a ausência de preparação para a saída da instituição e de apoio pós-colocação, acentuando a vulnerabilidade destes jovens a factores associados com a exclusão social (Taylor, 2004). 
Em função destas informações, parece-nos que a institucionalização encerra em si as duas "faces da mesma moeda": por um lado, pode permitir a capacitação para mudanças qualitativamente positivas, por outro, pode tornar-se numa resposta contraproducente e paradoxal para as crianças e jovens acolhidas.

348 No entanto, se a instituição estiver consciente dos seus objectivos, dispuser dos recursos mínimos necessários para os atingir e todos trabalharem em conjunto com vista a alcançá-los, tendo por finalidade a promoção do superior interesse da criança, o acolhimento institucional pode, de facto, servir como base de transição e mudança útil para a criança/adolescente (e suas famílias), permitindo assim a sua capacitação e a sua mobilização para transformações positivas e consistentes.

A institucionalização pode oferecer potencialidades que asseguram o interesse e bem-estar das crianças, e a passagem pela casinha de chocolate pode constituir uma etapa necessária e positiva na vida destas crianças, mas para tal é preciso que se faça uma avaliação objectiva de cada instituição e do próprio processo de institucionalização, que cruze indicadores de várias fontes. As narrativas dos sujeitos que aceitaram colaborar nesta investigação trouxeram algumas pistas, que poderão definir o início de um novo percurso, na vida das instituições.

\section{Referências bibliográficas}

Alberto, Isabel (2008). Como pássaros em gaiolas? Reflexões em torno da institucionalização de menores em risco. In Carla Machado \& Rui Abrunhosa Gonçalves (Coords.), Violência e Vitimas de crime, Vol.II: Crianças. $3^{\text {a }}$ edição (pp.209-227). Coimbra: Quarteto.

Barter, Christine (2003). Abuse of children in residential care. Retirado em Janeiro 6, 2009 de http://www.nspcc.org.uk/inform/research/Briefings/abuseofchildreninresidentialcare_wda48221.html.

Berger, Maurice (1998). A criança e o sofrimento da separação - Divórcio, adopção, colocação. Lisboa: Climepsi.

Berridge, David (1994). Foster and residential care reassessed: A research perspective. Children and Society, 8(2), 132-150.

Brazelton, Berry \& Greenspan, Stanley (2002). A criança e o seu mundo. Requisitos essenciais para o crescimento e a aprendizagem. Lisboa: Editorial Presença.

Carvalho, Maria (1999). Um passado, um presente, que futuro? Desvio e delinquências juvenis: aspirações e expectativas pessoais, escolares e profissionais de jovens em regime de internamento em Colégio do instituto de Reinserção Social. Infância e Juventude, 4, 9-148.

Cóias, João \& Simões, Isabel (1995). A componente de animação sócio-cultural na acção educativa em internato. Uma experiência no Instituto Navarra de Paiva. Infância e Juventude, 3, 73-82. 
Department of Health (1998). Caring for Children Away From Home. Messages from Research. Chichester: John Wiley and Sons.

Dias, Jorge \& Andrade, Manuel (1998). Criminologia - O Homem Delinquente e a Sociedade Criminógena. (pp. 178-241). Coimbra: Almedina.

Edmond, Ruth (2002). Understanding the resident group. Scottish Journal of Residential Care.Vol. 1 (1), 30-40.

Fernández del Valle, Jorge (1992). Evaluación de programas residenciales de Servicios Sociales para la infancia. Situación actual y aportacións de los enfoques ecopsicológicos. Psicothema, Vol.IV, (2), 531-542.

Goffman, Erving (1974). Manicómios, Prisões e Conventos. Colecção Debates. São Paulo: Perspectiva.

Instituto de Segurança Social, I.P. (2007). Plano de Intervenção Imediata. Relatório de Caracterização Sumária. Instituições de Acolhimento 2006. (pp. 1-21).

Kendrick, Andrew (1998). Abuse of Children in Residential and Foster Care: A Brief Review. Retirado em Outubro 20, 2008 de http://www.education.strath.ac.uk/sircc/research/kendrick.html

Linares, Juan (2002). El maltrato institucional. In Juan Luis Linares (Ed), Del abuso Y otros desmans (pp. 81-109). Barcelona: Paidós.

MacLeod, Mary (1999). The abuse of children in institutional settings: children's perspectives. In: Nick, Stanley; Jill, Manthorpe \& Bridgete Penhale (Eds), Institutional abuse - Perspectives across the life course (pp. 44-49). London: Ed. Routledge,

Madge, Nicola (1994). Children and Residential Care in Europe. London: National Children's Bureau.

Martins, Paula (2001). A avaliação como factor estruturante e promotor do desenvolvimento pessoal. Psicologia, Educação e Cultura, Vol. V(1), 63-70.

Martins, Paula (2004). Protecção de Crianças e Jovens em Itinerários de Risco. Representações, Espaços e Modos. Tese de doutoramento em Estudos da Criança. Universidade do Minho.

Martins, Paula (2005). O desenvolvimento pessoal e social da criança em contexto de vida institucional - elementos para uma análise da ecologia da interpessoalidade. In. https://repositorium.sdum.uminho.pt/handle/1822/6750.

Ministério da Justiça. Direcção Geral da Reinserção Social (2007). Relatório de Actividades. Retirado em Janeiro 14, 2009 de http://www.dgrs.mj.pt/c/portal/layout?p_I id $=$ PUB.1001.13.

Ministério do Trabalho e da Solidariedade (2000). Lares de Crianças e Jovens/Crianças e Jovens que Vivem em Lar. Lisboa. Instituto para o Desenvolvimento Social.

Mosteirin, Carmen (2000) El Fracasso de las instituciones para menores: Ineficácia, Ineficiência o Ideologia. In Actas do Congresso Internacional Os mundos sociais e culturais de infância, Vol.III. (pp. 72-75). Braga. Universidade do Minho.

Raymond, Marie (1999). Considerações acerca das perturbações do pensamento dos adolescentes. Infância e Juventude, 1, 9-112.

Raymond, Marie (1996a). Reflexões sobre o acompanhamento em instituição de adolescentes difíceis. Infância e Juventude, 2, 21-139.

Raymond, Marie (1996b). Reflexões sobre o acompanhamento em instituição de adolescentes difíceis. Infância e Juventude, 3, 35-116. 
Raymond, Marie (1998). Resposta aos Comportamentos Violentos em Instituição. Infância e Juventude, 3, 9-75.

Sandomingo, Juan (1998). Centros de Menores, de onte a hoxe. Santiago de Compostela: Xunta de Galicia.

Sousa, Liliana (2005). A relação com os serviços sociais. In Famílias Multiproblemática.s Quarteto, 45-83.

Taylor, Claire (2004). Justiça para Crianças Integradas no Sistema de Protecção. Infância e Juventude, 1, 56-77.

Teixeira, Mario (1993). Hospício e Poder. Brasília

Vilaverde, Maria (2000). Factores de Risco e Factores Protectores em Crianças Vitimas de Maus-tratos a Viver em Instituições. Tese de Mestrado não publicada, Universidade do Minho, Braga.

Zurita, Juan \& Fernández del Valle, Jorge (1996). Recursos residenciales para menores. In Joaquín Ochotorena, \& Maria Madariaga (Eds.), Manual de protección infantil. (393445). Barcelona: Masson.

\section{Once up on a time, in the Institution where I lived: adults' accounts on} the experiences of institutionalization

This study aimed to achieve a better understanding on the life-experiences of adults with experience in institutional care in childhood and/or adolescence, into two distinct cases: i) internment in a institution for child victims of violence and ii) detention in a young offenders' institution, after being found guilty of a crime. This study is based on the narrations of fourteen interviewees, focusing on what they perceived as positive and negative aspects of this experience, their experiences while institutionalized, as well as their suggestions in order to improve the quality of these services.

The results tend to show that institutionalization has positive and negative aspects that have been clearly identified by the participants of our study.

KEY-WORDS: institutionalization, life course, perceptions, narratives. 


\section{Il était une fois l'Institution où j'ai vécu: récits d'adultes sur leurs expériences de vie en institution}

L'étude élaborée dans cet article présente les expériences d'adultes ayant connu un épisode de vie au sein d'institutions liées au soin de l'enfance et/ou de l'adolescence, selon deux catégories distinctes : i) un long séjour en institution après avoir été identifié comme victimes de violence et ii) détenus dans une institution pour jeunes délinquants, après avoir été reconnus coupable de crime suivant la loi portugaise. Ce travail se fonde sur les interviews de quatorze personnes, et se focalise sur ce qu'ils ont perçu en tant qu'aspects positifs et négatifs dans cette expérience, ainsi que sur des suggestions proposées afin d'améliorer la qualité de ces services.

Les résultats semblent suggérer que l'institutionnalisation présente des aspects positifs autant que négatifs; ces aspects ont été clairement identifiés par les participants à notre étude.

MOTS-CLÉS: institutionnalisation, parcours, perceptions, narrations. 